\title{
scripted
}

Volume 13, Issue 1, May 2016

\section{REFLECTIONS ON A WORKSHOP WITH PROFESSOR SHEILA JASANOFF}

Emily Ross ${ }^{*}$

DOI: $10.2966 /$ scrip.130116.101

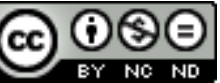
Licence. Please click on the link to read the terms and conditions.

* Research Fellow, The Centre for Population Health Sciences, Usher Institute of Population Health Sciences and Informatics, The University of Edinburgh 
On the $4^{\text {th }}$ March 2016, Early Career Researchers and PhD students from a range of disciplinary backgrounds including law, philosophy and sociology were pleased to be present at a workshop with Professor Shelia Jasanoff. Sheila Jasanoff is Pforzheimer Professor of Science and Technology Studies at Harvard University's John F. Kennedy School of Government. She is incredibly influential in her discipline, with her work exploring the co-production of science, technology and the social order.

Hosted by Dr Samuel Taylor-Alexander, part of the Wellcome Trust funded project Confronting the Liminal Spaces of Health Research Regulation based within the Mason Institute (PI: Professor Graeme Laurie), the workshop took as its starting point Professor Jasanoff's recent work on 'sociotechnical imaginaries'. ${ }^{1}$ This concept is used to explore collective visions of desirable futures as shaping scientific and technological projects. These visions are disseminated and re-enacted in and through national policies and institutions, encoding what is desirable and possible through science and technology, and shaping public hopes and expectations. ${ }^{2}$ In response to the focus of the Liminal Spaces project on research regulation presentations delivered by attendees throughout the workshop considered: scientific research as shaping and shaped by regulatory regimes, the enactment of sociotechnical imaginaries in research agendas, and how the reconfiguration of interfaces between technologies, regulatory processes and individuals may re-shape clinical practice.

Professor Jasanoff began the day with some reflections on contemporary controversies within science and technology, including the reformulation of understandings of citizenship and privacy by multinational companies such as Apple. Privacy was central to the first presentation of the workshop, given by Sophie Ilson ${ }^{3}$ who discussed efforts by the Scottish Government to improve public trust in data linkage, used by the government for statistical research and to improve service delivery. Sophie considered the operationalisation of the concept of privacy in debates around data linkage, and public expectations surrounding the use of personal data. This work prompted reflection on the relationship imagined between the state and the public as portrayed in the government's 'Data Vision for Scotland' strategy, and how such work may serve as an element of 'nation-building' ${ }^{4}$ in Scotland. Public trust was also implicit in Edward S. Dove's ${ }^{5}$ discussion of NHS research ethics committees (RECs). His talk explored the tensions inherent to the work of RECs, whose primary

\footnotetext{
${ }^{1}$ Sheila Jasanoff and Sang-Hyun Kim (eds) Dreamscapes of Modernity: Sociotechnical Imaginaries and the Fabrication of Power (Chicago: The University of Chicago Press. 2015)

${ }^{2}$ S Jasanoff, 'Future Imperfect: Science, Technology, and the Imaginations of Modernity' in Sheila Jasanoff and Sang-Hyun Kim (eds) Dreamscapes of Modernity: Sociotechnical Imaginaries and the Fabrication of Power (Chicago: The University of Chicago Press. 2015), pp. 1-33.

${ }^{3}$ Sophie Ilson: 'Data Linkage in Scotland: Exploring Public Trust through Public Engagement'

4 S Jasanoff Designs on Nature: Science and Democracy in Europe and the United States (Oxford: Princeton University Press, 2005)

${ }^{5}$ Edward S. Dove: 'Promoting Health Research and Protecting participants? The Impact of 'Nextgeneration' Health Research Regulation on NHS Research Ethics Committees’
} 
mandate has been to protect those participating in health-related research. He argued that in recent times, RECs have seen increasing emphasis on the promotion of research that will be of benefit to society, to the extent that this 'promotionist' stance is prioritised. This is visible in recent changes to the regulation of health research. Tensions inherent to thedual role of RECs as protecting participants, and as promoting research enabled Edward to ask questions about the role of research regulation in transforming understandings of human subjects, for example as beneficiaries or objects of research.

The entwinement of law and regulation with contemporary conceptualisations of what it means to be human were drawn upon in Laura Downey's ${ }^{6}$ presentation of her doctoral work. Laura considered the challenges posed by new and emerging science and technology (NEST), including techniques such as gene editing and mitochondrial replacement, to existing legal and regulatory concepts. Laura argued that the reformulation of law and regulation in response to these emergent techniques is revealing with regards how identity is conceptualised by institutions and publics, in terms of personhood, rights and responsibilities. Similarly, understandings of identity are responsive to social and legal debates around these technological developments. Laura's work thus demonstrated that the regulation of new and emerging science and technology is emblematic of the co-production of science and its regulation, and society. ${ }^{7}$ Emily Postan's ${ }^{8}$ work also considered identity, though at the level of the individual. Drawing on philosophical bioethics, Emily discussed how personal 'bioinformation' (such as findings from biomedical research), and in turn regulation governing access to this information, may contribute to the construction of narrative identity. The significance of information such as genetic data, or, with regards to donor conception, to 'ways of being human' in the $21^{\text {st }}$ century is reflected in and promoted through regulation. As highlighted by Professor Jasanoff in the ensuing discussion, in the contemporary era, regulatory regimes often privilege social roles and relationships understood to be 'natural'. Tineke Broer and Emily Ross ${ }^{10}$ also discussed contemporary transformations of human experience and the categories used to make sense of this. Their talk considered how future treatments and techniques of surveillance, made possible by genomic research, may transform the experience of being a patient. These transformations have the potential to extend 'patienthood' beyond the presence of pathology, exposing new elements of illness trajectories to medical intervention, and producing novel forms of patient data.. Relating to Emily

\footnotetext{
${ }^{6}$ Laura Downey: 'The Law of Identity and the Identity of the Law: Investigating the Dynamics of Identity in Changing Socio-Technical Environments and its Construction within and Shaping of Law and Regulation'

7 S Jasanoff (ed), (States of Knowledge: The Co-production of Science and the Social Order (London: Routledge, 2004)

${ }^{8}$ Emily Postan: 'Attending to Identity Interests in the Regulation of Access to Individual Research Findings'

9 I Hacking Rewriting the Soul: Multiple Personality and the Sciences of Memory (Princeton, N.J.: Princeton University Press, 1998)

${ }^{10}$ Tineke Broer and Emily Ross: 'Regulating Cancer Patienthood in the Post-genomic Era'
} 
Postan's talk, such developments may have consequences for the types of bioinformation that are producible, and to what extent patients and research participants have a right to access, or refuse access to, such data. Bringing a social scientific lens to a setting characterised by scientists and technological innovation was also discussed by Abby King ${ }^{11}$. Abby's work explored the use of health information technologies to promote the appropriate use of antimicrobials amongst physicians, in the context of the problem of increasing global resistance to these medicines. By exploring how these technologies are used in existing settings, and paying particular attention to the broader social contexts in which they are developed, Abby's work hopes to provide insights for the implementation of these techniques in the UK.

Also addressing novel forms of policy-relevant science, Isabel Fletcher's ${ }^{12}$ presentation focused on the integration of 'sustainability' into healthy eating guidelines. Isabel considered how these two separate bodies of scientific knowledge have become integrated and integrate-able, and also how resulting policy embodies sociotechnical imaginaries of particular global futures. Professor Jasanoff encouraged reflection on the kinds of citizens that are produced and imagined through these guidelines, and also on the strategies of choice architecture observable in food-related regulation and policy.

Overall, the workshop presented a wonderful opportunity for early careers scholars to share their research with others, and to gain feedback from a pioneer in the field of science and technology studies. Professor Jasanoff's insights encouraged participants to consider the political economy providing the backdrop to shifts and innovation in regulation, and also prompted reflection on a wider scale, situating our research in a global context characterised by inequality.

\footnotetext{
${ }^{11}$ Abby King: 'Innovative Approaches and Transferable Lessons: Investigating International IT-based Strategies in Antimicrobial Stewardship'

12 Isabel Fletcher: 'Eating Less Meat 'to Save the Planet'? Understanding the Complexities of Developing Sustainable Healthy Eating Advice’
} 